\title{
Combustion and Pyrolysis Kinetics of Chloropicrin
}

\author{
J.-C. Lizardo-Huerta ${ }^{1}$, B. Sirjean ${ }^{1}$, L. Verdier $^{2}$, R. Fournet $^{1}$, P.-A. Glaude ${ }^{1 *}$ \\ ${ }^{1}$ Laboratoire Réactions et Génie des Procédés, CNRS, Université de Lorraine \\ 1 rue Grandville BP 2045154001 Nancy Cedex, France
}

${ }^{2}$ DGA Maîtrise NRBC, Site du Bouchet, 5 rue Lavoisier, BP n³, 91710 Vert le Petit, France

Corresponding author :

Pierre-Alexandre Glaude

Laboratoire Réactions et Génie des Procédés

1 rue Grandville BP 2045154001 Nancy Cedex,

France

Email:pierre-alexandre.glaude@univ-lorraine.fr 


\begin{abstract}
Chloropicrin $\left(\mathrm{CCl}_{3} \mathrm{NO}_{2}\right)$ is widely used in agriculture as a pesticide, weed-killer, fungicide or nematicide. It has also been used as chemical agent during World War I. The precise understanding of its combustion chemistry for destruction processes or in the event of accidental fire of stored reserves is a major safety issue. A detailed chemical kinetic model for the combustion and pyrolysis of chloropicrin is proposed for the first time. A large number of thermo-kinetic parameters were calculated using quantum chemistry and reaction rate theory. The model was validated against experimental pyrolysis data available in the literature. It was shown that the degradation of chloropicrin is ruled by the breaking of the $\mathrm{C}-\mathrm{N}$ bond followed by the oxidation of the trichloromethyl radical by $\mathrm{NO}_{2}$ through the formation of the adduct $\mathrm{CCl}_{3} \mathrm{ONO}$, which can decompose to $\mathrm{NO}$, chlorine atom and phosgene. Phosgene is much more stable than chloropicrin and its decomposition starts at much higher temperatures. Combustion and pyrolysis simulations were also compared and demonstrated that the addition of oxygen has very little effect on the reactivity or product distribution due to the absence of hydrogen atoms in chloropicrin.
\end{abstract}




\section{Introduction}

Chloropicrin $\left(\mathrm{CCl}_{3} \mathrm{NO}_{2}\right)$ is a nitroaliphatic compound, also known as trichloronitromethane. It is a colorless liquid which volatilizes slowly at room temperature and atmospheric pressure. Chloropicrin has been widely used as herbicide, repellent, fumigant, insecticide, nematicide and disinfectant ${ }^{1,2}$. It was also found to be an efficient chemical agent during World War, as a tear and a vomiting gas, also known as acquinite, G-25, S-1 or PS ${ }^{3,4}$. Despite its little prevalence in environment, its high toxicity and environmental concerns have led to the prohibition of agricultural uses in Europe, but chloropicrin is still involved in many treatments in other countries, including the US for soil fumigation ${ }^{5}$. The evaluation of danger in case of accidental fire and the destruction by thermal treatments of excess quantities of pesticides as well as stockpiles or unexploded ammunitions still found every year on old battlefields, requires the development of highly safe processes ${ }^{6}$. The yields of toxic emissions from incinerations or other thermal destruction processes are mostly controlled by chemical kinetics.

Few quantitative experimental studies have been devoted to chloropicrin thermal decomposition ${ }^{7-11}$. High toxicity of this compound induces a high level of complexity for any experiments. Consequently, there is a considerable lack of knowledge on the behavior of this chemical under high-temperature conditions with or without oxygen. Chloropicrin is an active chemical species, which manifests low bond dissociation energies (BDE) compared to hydrocarbons. Our calculations at the CBS-QB3 level of theory show that the BDE of the C$\mathrm{Cl}$ and $\mathrm{C}-\mathrm{N}$ bonds are 68.9 and $42.1 \mathrm{kcal} \mathrm{mol}^{-1}$ respectively (Fig. 1). Note that chloropicrin, which does not contain any $\mathrm{H}$-atom, is known as non-combustible, but enhances the reactivity of combustible mixtures and broaden the flammability limits of gas mixtures thanks to the oxidant role of the $\mathrm{NO}_{2}$ function ${ }^{12,13}$. 


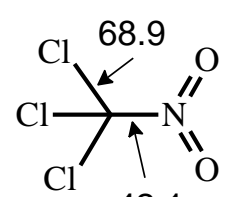

42.1

Figure 1. Bond dissociation energies at $298 \mathrm{~K}$ in chloropicrin computed at the CBS-QB3 level of theory (in $\mathrm{kcal} \mathrm{mol}^{-1}$ ).

The first analytical attempts demonstrated that the decomposition of chloropicrin starts at its boiling temperature $\left(\sim 112^{\circ} \mathrm{C}\right)$ and that the main products of decomposition are phosgene $\left(\mathrm{COCl}_{2}\right)$ and nitrosyl chloride $(\mathrm{ClNO})^{7}$. Radulescu and Zemfirecu ${ }^{8}$ later measured the global rate of decomposition in the temperature range $130-160^{\circ} \mathrm{C}$ and found an activation energy around $40 \mathrm{kcal} \mathrm{mol}^{-1}$, which is consistent with a reaction occurring mainly by the unimolecular breaking of the $\mathrm{C}-\mathrm{N}$ bond, which $\mathrm{BDE}$ equals $42.1 \mathrm{kcal} \mathrm{mol}^{-1}$ (Fig. 1). In 1938, Steacie and $\mathrm{Smith}^{9}$ pyrolyzed chloropicrin between 138 and $170^{\circ} \mathrm{C}$. Their study confirmed that the reaction occurs by a unimolecular decomposition producing phosgene and nitrosyl chloride. The authors obtained a high pressure limit rate constant of $4.90 \times 10^{15}$ exp $^{-}$ 18958/T $\mathrm{s}^{-1}$. They also observed that, under these temperature conditions, CINO decomposed slowly to $\mathrm{NO}$ and $\mathrm{Cl}$ and concluded that the main products of chloropicrin decomposition are $\mathrm{COCl}_{2}$ and an equilibrium mixture of $\mathrm{ClNO}, \mathrm{NO}$ and $\mathrm{Cl}_{2}$. Experimental work by Dubikhin et al. ${ }^{10}$ in 1971 on the same temperature range led to rate constant of $2.24 \times 10^{15} \exp ^{-18837 / T} \mathrm{~s}^{-1}$, in very good agreement with previous data ${ }^{8,9}$. The authors observed that the reaction depends on pressure below 300 Torr. A more recent experimental work was carried out by Battin-Leclerc et al. ${ }^{11}$. In this work, the decomposition of chloropicrin under pyrolysis conditions was studied for temperatures ranging from 100 to $530^{\circ} \mathrm{C}$ in an isothermal closed reactor at an initial pressure of 25 Torr ( 0.033 bar) and for reaction times ranging between 10 and $120 \mathrm{~min}$. According to this work, phosgene is the main carbon containing reaction product; the other quantified products are majorly $\mathrm{NO}$ and $\mathrm{Cl}_{2}$ and the less important are $\mathrm{CO}$ and $\mathrm{CCl}_{4}$. 
These studies show potential conditions for the destruction of chloropicrin, however to our knowledge there is no detailed kinetic model for the description of chloropicrin chemistry. Following a methodology used for other chemical agents such as yperite (sulfur mustard) and HN-3 (nitrogen mustard) ${ }^{14,15}$ and more recently phosgene and diphosgene ${ }^{16}$, a comprehensive detailed kinetic model for the thermal decomposition and the combustion of chloropicrin has been developed in this work and validated against available experimental data.

\section{Computational methods}

Calculations from quantum chemistry were used to evaluate the high-pressure kinetic constants and thermodynamic data $\left(\Delta_{\mathrm{f}} \mathrm{H}^{\circ}{ }_{298 \mathrm{~K}}, \mathrm{~S}^{\circ}{ }_{298 \mathrm{~K}}, \mathrm{C}^{\circ} \mathrm{P}(\mathrm{T})\right)$ associated with elementary processes involved in the primary mechanism of chloropicrin thermal decomposition, that are not available in the literature. Note that barrierless reactions, such as unimolecular initiations and radical combinations, which do not involve a defined transition state, were not treated theoretically. The calculations of the electronic structure of the reactants, products and transition states have been computed at the CBS-QB3 level of theory. This composite method involves a geometry optimization at the B3LYP/6-311G(2d,d,p) level of calculation and energy computations using several levels of theory. A basis set extrapolation allows to estimate a "complete basis set" (CBS) energy ${ }^{17,18}$. In addition, an analysis of vibrational frequencies was systematically performed to confirm the nature of the transition states (TS). In the cases where the imaginary frequency is not non-ambiguously related to the reaction coordinate, the Intrinsic Reaction Coordinate (IRC) approach ${ }^{19}$ has been used to ensure the correct connection between a given transition state structure and the reactant and product. In this study, all the calculations have been performed using the GAUSSIAN 09 Rev. B.01 software ${ }^{20}$. For all the studied molecules, the enthalpies of formation have been evaluated using atomization reaction energies ${ }^{21}$. The references for atomization energies of atoms were taken from the CODATA database ${ }^{22}$. Spin-orbit corrections have been taken into account ${ }^{23}$. 
This methodology has proven its precision with molecules containing hetero-atoms ${ }^{15,16,24}$. In addition, the low frequency vibration modes, corresponding to internal rotations, were treated as hindered rotors instead of harmonic oscillators, using THERMROT ${ }^{25}$. This in-house code allows a one-dimensional hindered rotor (1D-HR) treatment of internal rotations and avoids the coupling of torsional modes encountered in the frequency analysis made by Gassian09, using the method proposed by Vansteenkiste et al. ${ }^{26}$. 1D-HR treatment was used with torsional potential calculated from relaxed scans computed at the B3LYP/6-311G(2d,d,p) level of theory. Rate constant were eventually calculated as a function of temperature thanks to the Transition State Theory. The high pressure limit kinetic rate constants were fitted using the three parameter modified Arrhenius equation $\left(A \times T^{n} \times \exp \left(-E_{a} / R T\right)\right)$ over the temperature range $300-2000 \mathrm{~K}$.

\section{Chemical kinetic model development}

The detailed kinetic model for the thermal decomposition of chloropicrin is composed of three sub-mechanisms: a first part corresponding to the decomposition of nitrogen species, another one dedicated to chlorinated species, and a mechanism specific to the decomposition and oxidation of chloropicrin and derived products.

Reactions of nitrogen species are taken from the mechanism proposed by Konnov et al. ${ }^{27}$. Since chloropicrin just involves $\mathrm{C}, \mathrm{N}$, and $\mathrm{Cl}$ atoms, the species containing hydrogen atoms in their chemical structure have been removed. In the same way, the sub-mechanism for chlorinated species has been adapted from the mechanism of Leylegian et al. ${ }^{28}$ for the reactions of chloromethanes where hydrogen containing species have been removed. Recently, a new mechanism for $\mathrm{HCl}$ combustion has been proposed by Pelucchi et al. ${ }^{29}$ which notably updates the reactions of light chlorinated compounds and re-examines the mechanism of flame inhibition involving the $\mathrm{HCl} / \mathrm{Cl}_{2}$ system. Thus, we added to the mechanism of Leylegian et al. all the missing reactions and updated some kinetic data of reactions that 
appeared in both mechanisms. Some reactions of polychloromethanes not included in the previous mechanisms were also taken into account from the kinetic model proposed by Drakon and Eremin ${ }^{30}$.

A mechanism specific to chloropicrin has been developed in this work, in which were included unimolecular initiations, chlorine-atom abstractions, decomposition of the radicals formed, chlorine-nitrogen coupling reactions, as well as some oxidation reactions not included in kinetic models of chlorinated and nitrogenous species. The thermochemical properties were taken from the literature in the case of light species involved in the nitrogen and chlorine sub-mechanisms ${ }^{27-29}$, and theoretically calculated for chloropicrin and related products. Main species theoretically studied are presented in Table 1. The kinetic constants were either taken from the literature or theoretically obtained using the CBS-QB3 level of theory or estimated by analogy with similar reactions of the chlorinated species. The details of this mechanism will be presented in the following.

Table 1: Thermochemical properties of chloropicrin and related species determined at the CBS-QB3 level of theory.

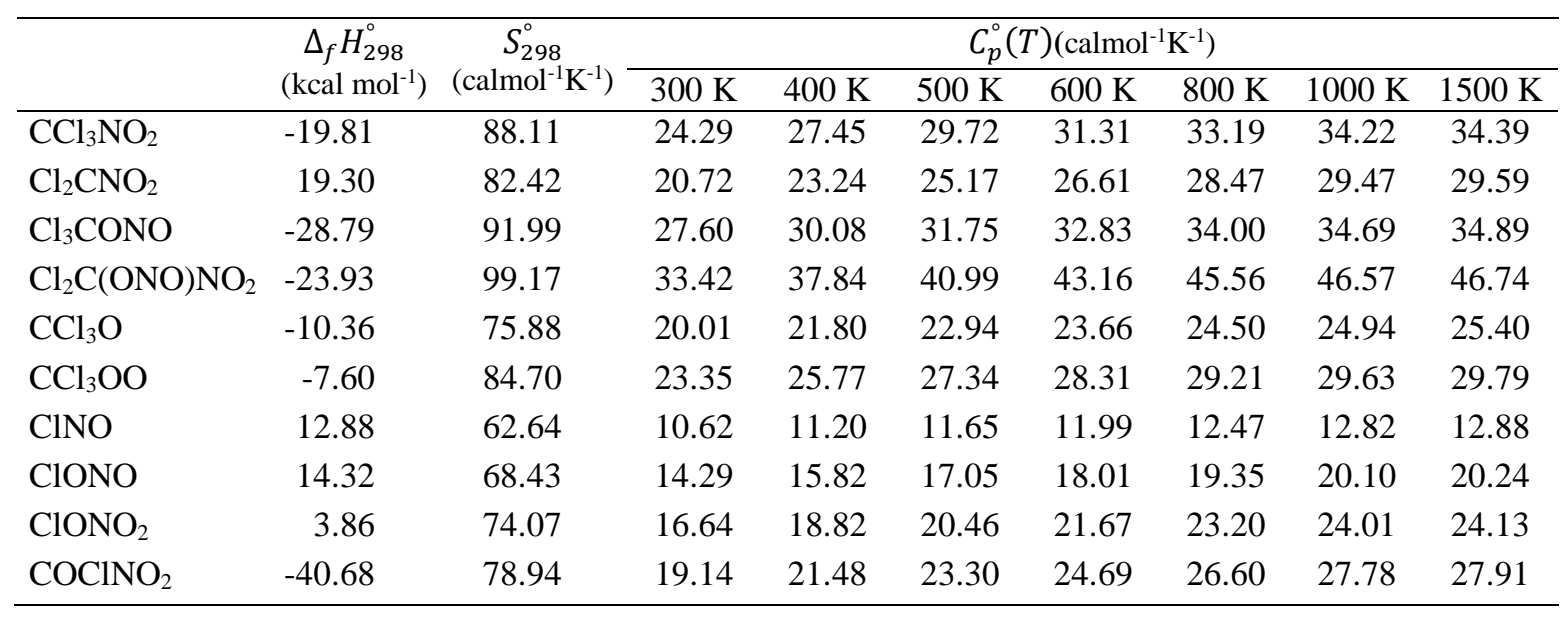

\section{Mechanism specific to chloropicrin}

Possible unimolecular initiation reactions involve the rupture of the $\mathrm{C}-\mathrm{N}$ and $\mathrm{C}-\mathrm{Cl}$ bonds, with the first being the easiest (BDE 42.1 vs. $68.9 \mathrm{kcal} \mathrm{mol}^{-1}$, Fig. 1). Reactions were written in the reverse direction as barrierless radical combinations (reactions (1) and (2) in Table 2). 
The kinetic constant of the first reaction was estimated from the correlations involved in the EXGAS software ${ }^{31}$ and that of the second one by analogy with the reaction $\mathrm{CCl}_{3}+\mathrm{Cl}^{32}$ which produces a $\mathrm{C}-\mathrm{Cl}$ bond with a close $\mathrm{BDE}$. Decomposition reactions of the produced radicals were included, based on analogies with species featuring similar chemical structures, like $\mathrm{CH}_{3} \mathrm{NO}_{2}{ }^{33}, \mathrm{CHCl}_{2} \mathrm{NO}_{2}{ }^{34}$ and $\mathrm{C}_{2} \mathrm{Cl}_{3} \mathrm{NO}_{2}{ }^{35}$. The authors showed that $\mathrm{NO}_{2}$ and the carbon radicals $\left(\mathrm{CH}_{3}, \mathrm{CHCl}_{2}\right.$ or $\left.\mathrm{C}_{2} \mathrm{Cl}_{3}\right)$ react by combination to form either the reactant (addition of the $\mathrm{N}$ side of $\mathrm{NO}_{2}$ ) or a $\mathrm{R}-\mathrm{ONO}$ species (addition of the $\mathrm{O}$ side of $\mathrm{NO}_{2}$ ). These combinations are barrierless. To better understand this behavior, the potential energy surface for the primary decomposition of chloropicrin was calculated (Fig. 2).

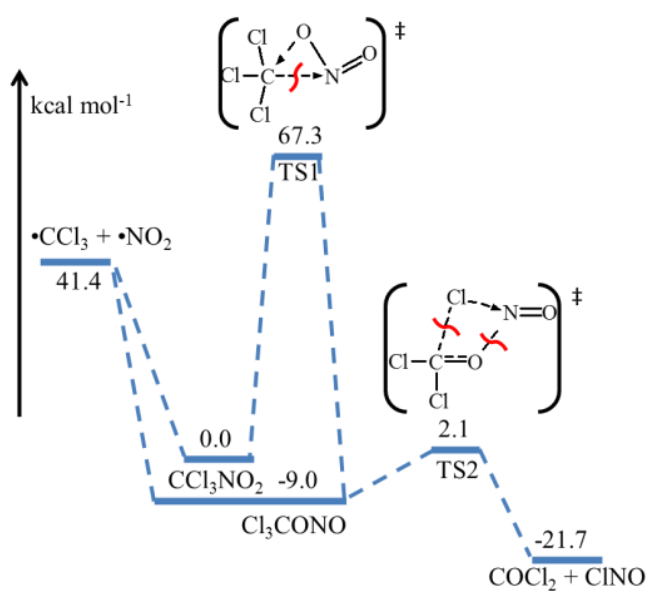

Figure 2.Energy profile at $0 \mathrm{~K}$ of the primary decomposition of chloropicrin, computed at the CBS-QB3 level of theory (in kcal mol-1).

In Fig. 2, the combination of $\mathrm{CCl}_{3}$ with $\mathrm{NO}_{2}$ on the $\mathrm{O}-\mathrm{NO}$ side produced $\mathrm{Cl}_{3} \mathrm{CONO}$, which lies about $9 \mathrm{kcal} \mathrm{mol}^{-1}$ below chloropicrin $\left(\mathrm{CCl}_{3} \mathrm{NO}_{2}\right)$. The latter can directly interconvert into $\mathrm{Cl}_{3} \mathrm{CONO}$ (TS1 and reaction 3 in Table 2) but the energy barrier is high $\left(67.3 \mathrm{kcal} \mathrm{mol}^{-1}\right)$ and remains much above the exit channel yielding trichloromethyl and $\mathrm{NO}_{2}$. Meanwhile, $\mathrm{Cl}_{3} \mathrm{CONO}$ decomposes easily through a cyclic transition state (TS2 and reaction 4 in Table 2), in which a $\mathrm{Cl}$-atom is transferred on the $\mathrm{N}$-atom, while the $\mathrm{O}-\mathrm{N}$ bond breaks to produce 
$\mathrm{ClNO}$ and phosgene $\mathrm{COCl}_{2}$. The geometry of TS2 is displayed in Fig. 3. The energy barrier is only $11.1 \mathrm{kcal} \mathrm{mol}^{-1}$ at $0 \mathrm{~K}$. To verify the connection between the reactant and the products, an IRC calculation at the B3LYP/6-311G(2d,d,p) level of calculation was performed. Chloropicrin will then readily react by an initial $\mathrm{C}-\mathrm{N}$ bond breaking and the combination of produced radicals will further produce $\mathrm{Cl}_{3} \mathrm{CONO}$ (reaction 5). The latter can decompose by reaction 4 through TS2, or by the $\mathrm{O}-\mathrm{NO}$ bond breaking (bond dissociation energy $40.1 \mathrm{kcal}$ mol $^{-1}$ ) yielding $\mathrm{CCl}_{3} \mathrm{O}$ radicals and $\mathrm{NO}$ (reaction 6), which rate constant was set equals to that of $\mathrm{CH}_{3} \mathrm{ONO}{ }^{36}$. The rate parameter of the decomposition of $\mathrm{CCl}_{3} \mathrm{O}$ to phosgene and $\mathrm{Cl}$-atom was calculated theoretically (reaction 7).

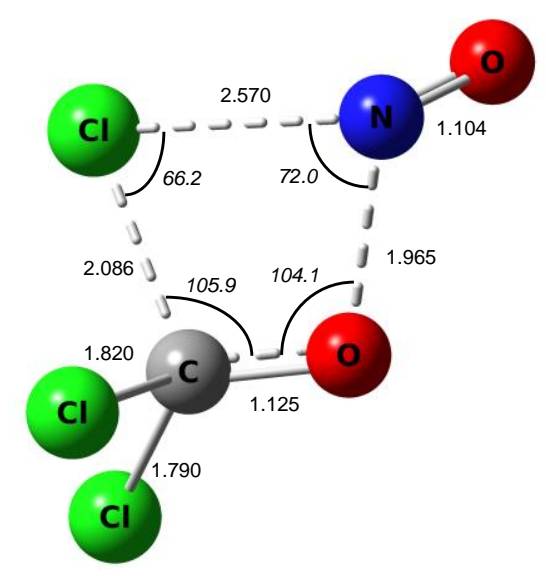

Figure 3. CBS-QB3 geometry of chloropicrin transition state TS2. Bond length in Á, angle in degree. CONO dihedral angle is $101.2^{\circ}$.

Table 2. Reactions of decomposition of chloropicrin and its primary products. Units are $\mathrm{cm}^{3}$, mol, s, cal with $\mathrm{k}=\mathrm{A} \mathrm{T}^{\mathrm{n}} \exp (-\mathrm{E} / \mathrm{RT})$.

\begin{tabular}{llccccc} 
Reaction & $\mathbf{A}$ & $\mathbf{n}$ & $\mathbf{E}$ & $\mathbf{k} 5 \mathbf{5 0 \mathbf { K }}$ & \\
\hline (1) & $\mathrm{CCl}_{3}+\mathrm{NO}_{2} \leftrightarrows \mathrm{CCl}_{3} \mathrm{NO}_{2}$ & $2.0 \times 10^{12}$ & 0.0 & 0.0 & $2.0 \times 10^{12}$ & Est. ${ }^{31}$ \\
\hline$(2)$ & $\mathrm{Cl}_{2} \mathrm{CNO}_{2}+\mathrm{Cl} \leftrightarrows \mathrm{CCl}_{3} \mathrm{NO}_{2}$ & $3.52 \times 10^{13}$ & 0.0 & 0.0 & $3.5 \times 10^{13}$ & Est. ${ }^{32}$ \\
\hline$(3)$ & $\mathrm{CCl}_{3} \mathrm{NO}_{2} \leftrightarrows \mathrm{Cl}_{3} \mathrm{CONO}$ & $3.86 \times 10^{11}$ & 0.924 & 67728 & $3.0 \times 10^{-16}$ & theory \\
\hline (4) & $\mathrm{Cl}_{3} \mathrm{CONO} \leftrightarrows \mathrm{COCl}_{2}+\mathrm{ClNO}$ & $8.51 \times 10^{11}$ & 0.343 & 11362 & $7.7 \times 10^{7}$ & theory \\
\hline
\end{tabular}




\begin{tabular}{llccccc}
\hline (5) $\quad \mathrm{CCl}_{3}+\mathrm{NO}_{2} \leftrightarrows \mathrm{Cl}_{3} \mathrm{CONO}$ & $2.0 \times 10^{13}$ & 0.0 & 0.0 & $2.0 \times 10^{13}$ & Est. ${ }^{31}$ \\
\hline (6) $\quad \mathrm{Cl}_{3} \mathrm{CONO} \leftrightarrows \mathrm{CCl}_{3} \mathrm{O}+\mathrm{NO}$ & $1.06 \times 10^{15}$ & 0.0 & 35970 & $2.0 \times 10^{-1}$ & Est. ${ }^{36}$ \\
\hline (7) $\quad \mathrm{CCl}_{3} \mathrm{O} \leftrightarrows \mathrm{COCl}{ }_{2}+\mathrm{Cl}$ & $1.52 \times 10^{13}$ & 0.201 & 17797 & $8.8 \times 10^{5}$ & theory \\
\hline (8) $\quad \mathrm{CCl}_{3} \mathrm{NO}_{2}+\mathrm{Cl} \leftrightarrows \mathrm{Cl}_{2} \mathrm{CNO}_{2}+\mathrm{Cl}_{2}$ & $9.37 \times 10^{08}$ & 1.784 & 17556 & $1.3 \times 10^{6}$ & Est. ${ }^{37}$ \\
\hline (9) $\mathrm{Cl}_{2} \mathrm{CNO}_{2} \leftrightarrows \mathrm{COCl}_{2}+\mathrm{NO}$ & $2.46 \times 10^{12}$ & 0.485 & 61558 & $6.2 \times 10^{-14}$ & theory \\
\hline (10) $\mathrm{Cl}_{2} \mathrm{CNO}_{2}+\mathrm{NO}_{2} \leftrightarrows \mathrm{Cl}_{2} \mathrm{C}(\mathrm{ONO}) \mathrm{NO}_{2}$ & $2.0 \times 10^{12}$ & 0.0 & 0.0 & $2.0 \times 10^{12}$ & Est. ${ }^{31}$ \\
\hline (11) $\mathrm{Cl}_{2} \mathrm{C}(\mathrm{ONO}) \mathrm{NO}_{2} \leftrightarrows \mathrm{COClNO}_{2}+\mathrm{ClNO}$ & $9.17 \times 10^{13}$ & -0.350 & 11189 & $1.3 \times 10^{8}$ & theory \\
\hline (12) $\mathrm{Cl}_{2} \mathrm{C}(\mathrm{ONO}) \mathrm{NO}_{2} \leftrightarrows \mathrm{COCl}_{2}+\mathrm{N}_{2} \mathrm{O}_{3}$ & $1.12 \times 10^{14}$ & -0.104 & 23850 & $2.2 \times 10^{3}$ & theory \\
\hline
\end{tabular}

The chlorine atom abstraction reaction was also considered (reactions 8). The kinetic parameters were estimated by analogy with the $\mathrm{Cl}$-atom abstraction from $\mathrm{CCl}_{4}$ calculated theoretically by Brudnik et al. ${ }^{37}$. The values were recalculated from the high-pressure limit rate constant given in the paper. The radical $\mathrm{Cl}_{2} \mathrm{CNO}_{2}$ can decompose by a rearrangement reaction, in which an oxygen atom from the nitro group is transferred to the carbon atom (reaction 9). The $\mathrm{C}-\mathrm{N}$ and $\mathrm{N}-\mathrm{O}$ bonds break simultaneously forming $\mathrm{COCl}_{2}$ and $\mathrm{NO}$ as products (Fig. 4). The combination of $\mathrm{Cl}_{2} \mathrm{CNO}_{2}$ with $\mathrm{NO}_{2}$ to yield $\mathrm{Cl}_{2} \mathrm{C}(\mathrm{ONO}) \mathrm{NO}_{2}$ (reaction 10) and the subsequent decompositions were also written by analogy with $\mathrm{Cl}_{3} \mathrm{CONO}$ and the rate of the subsequent decompositions calculated theoretically (reactions 11-12).

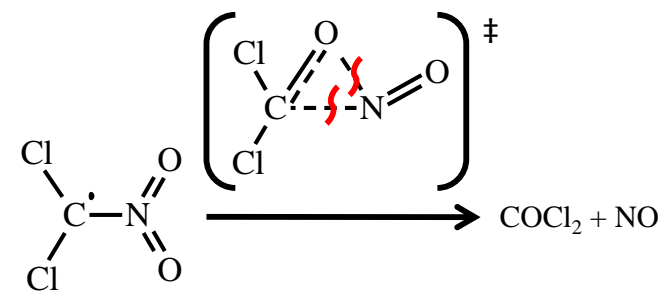

Figure 4. Reaction of rearrangement-elimination of radical $\mathrm{CCl}_{2} \mathrm{NO}_{2}$.

The decomposition reactions of the primary products were also included. Reactions of phosgene $\mathrm{COCl}_{2}$ were taken from a previous study ${ }^{16}$. Reactions of nitrosyl chloride CINO, and reactions of coupling between light chlorine and nitrogen containing species were taken from the literature or by analogy with equivalent reactions ${ }^{38-40}$. 


\section{Results and discussion}

The detailed kinetic model for the thermal decomposition of chloropicrin is composed of 54 species and 207 reactions and is available as Supplemental material. The Senkin program of

Chemkin II ${ }^{41}$ was used to perform simulations of the decomposition of chloropicrin under pyrolysis conditions in a close vessel. The simulations were done for temperatures ranging from 100 to $500^{\circ} \mathrm{C}$, the reactor volume was $350 \mathrm{~cm}^{3}$, the initial pressure was set at 25 Torr (0.033 bar) and the residence time up to 10 minutes. These conditions correspond to the experimental study on the thermal decomposition of chloropicrin carried out by BattinLeclerc et al. ${ }^{11}$.

Figure 5 shows the total pressure profiles as a function of residence time at different temperatures. Simulations are in very good agreement with the experimental results, without any fitting of rate constants, considering the experimental uncertainties due to the initial injection of the liquid reactant ${ }^{11}$. The constant pressure observed at $100^{\circ} \mathrm{C}$ implies that liquid chloropicrin is quickly vaporized after its injection into the reactor (the saturating vapor pressure of chloropicrin at $20^{\circ} \mathrm{C}$ is 20.25 Torr) and that no further reaction occurs thereafter. The increase of pressure with time at $200^{\circ} \mathrm{C}$ indicates the onset of a slow chloropicrin decomposition. At $400^{\circ} \mathrm{C}$, the pressure increases almost instantly after injection up to 66 Torr experimentally indicating that the chloropicrin is completely decomposed, but the very little change of the pressure over the next 10 min denotes a little reactivity of first reaction products at this temperature. The further increase in pressure at $500^{\circ} \mathrm{C}$ implies the occurrence of secondary decomposition reactions of the primary products. The model reproduces well these different behaviors at the different temperatures. 


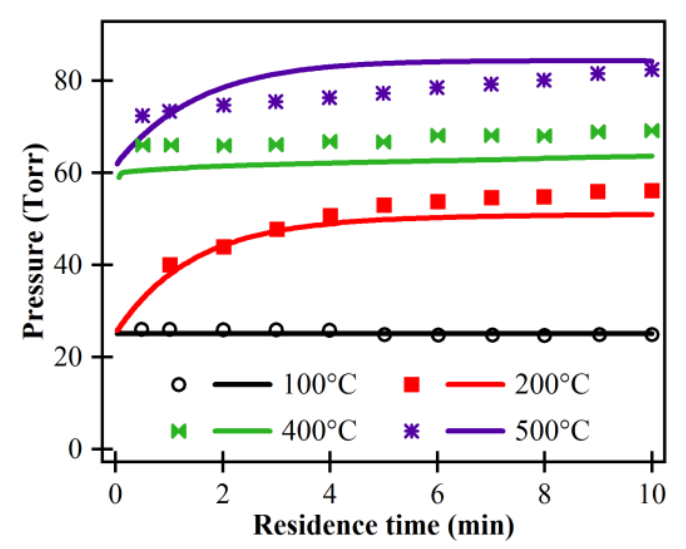

Figure 5.Profiles of pressure $v s$. residence time for the thermal decomposition of chloropicrin. Initial pressure, 25 Torr. Symbols: experimental results ${ }^{11}$; lines: simulation.

The experimental conversion of chloropicrin presented in Figure 6 as a function of temperature, for a fixed residence time of $10 \mathrm{~min}$, is well predicted by the simulations. Under these conditions, chloropicrin begins to decompose below $150^{\circ} \mathrm{C}$ and is totally destroyed around $200^{\circ} \mathrm{C}$.

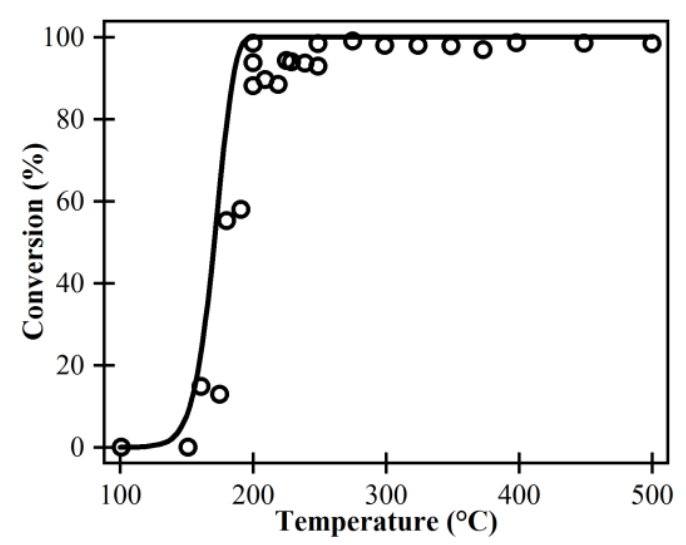

Figure 6. Conversion of chloropicrin vs. temperature. Initial pressure, 25 Torr; residence time, 10 min. Symbols: experimental results ${ }^{11}$; lines: simulation.

Figure7 shows the evolution of the partial pressures of experimentally quantified products as a function of the temperature, for a residence time of $10 \mathrm{~min}$. Results of simulations agree well for the main products, i.e. $\mathrm{NO}$ and phosgene. For $\mathrm{CCl}_{4}$, model predictions are correct for 
temperatures below $300^{\circ} \mathrm{C}$, but underestimate them at higher temperatures. Note that wallpromoted combinations of $\mathrm{CCl}_{3}$ radicals with $\mathrm{Cl}$-atoms cannot be disregarded. In the case of NO, the simulated profile displayed in Fig. 7 is the sum of the calculated mole fraction of NO and NOCl. This latter was indeed not detected in the experiments by Battin-Leclerc et al. ${ }^{11}$, whereas it was found to be the primary product of chloropicrin decomposition in previous experimental studies ${ }^{7,9,10}$. The very low $\mathrm{Cl}-\mathrm{NO}$ BDE $\left(37.2 \mathrm{kcal} \mathrm{mol}^{-1}\right)$ makes almost impossible the quantification of the species by gas-phase chromatography, and we assumed that nitrosyl chloride decomposed completely into $\mathrm{NO}$ and $\mathrm{Cl}$ during the analytical process. The model slightly overestimates the formation of $\mathrm{NOCl}$ at $225^{\circ} \mathrm{C}$. However, for temperatures above $300^{\circ} \mathrm{C}$ a good agreement is obtained. With regard to phosgene, model predictions are in good agreement with the experimental results. This compound is a primary product of chloropicrin decomposition, which shows a much stronger thermal stability than the parent molecule. The decomposition of the phosgene starts to be noticeable around $370^{\circ} \mathrm{C}$ in these conditions ${ }^{16}$.

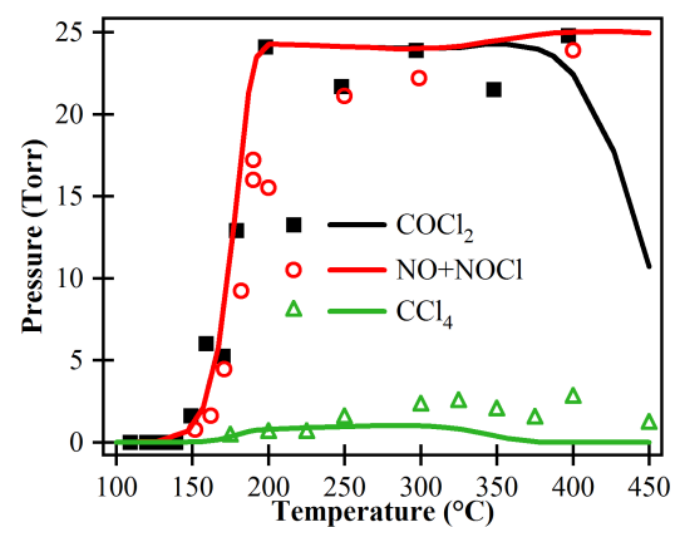

Figure 7. Products quantified during the thermal decomposition of chloropicrin. Initial pressure, 25 Torr; residence time, $10 \mathrm{~min}$. Symbols: experimental results ${ }^{11}$; lines: simulation.

In conditions of Fig. 7, chloropicrin decomposes to $\mathrm{CCl}_{3}$ and $\mathrm{NO}_{2}$ over the entire temperature range, the $\mathrm{Cl}$-atom abstraction remaining negligible. These products combine then together to 
yield $\mathrm{CCl}_{3} \mathrm{ONO}$, which rapidly decomposes into phosgene and $\mathrm{ClNO}$. Note that the global reaction $\mathrm{CCl}_{3} \mathrm{NO}_{2}=\mathrm{COCl}_{2}+\mathrm{ClNO}$ is strongly exothermic by $19.9 \mathrm{kcal} / \mathrm{mol}$, as usual for the decomposition of $\mathrm{NO}_{2}$-containing species. Nitrosyl chloride reacts by $\mathrm{Cl}$-atom abstractions by $\mathrm{Cl}$ atoms, $\mathrm{NO}_{2}$ and in a lesser extent $\mathrm{CCl}_{3}$, producing $\mathrm{NO}$ and $\mathrm{Cl}_{2}, \mathrm{ClNO}_{2}$, and $\mathrm{CCl}_{4}$ respectively. Reactions with $\mathrm{Cl}$-atoms and $\mathrm{CCl}_{3}$ are very exothermic (enthalpy of reaction of 20.3 and $-35.5 \mathrm{kcal} \mathrm{mol}^{-1}$, respectively), that with $\mathrm{NO}_{2}$ slightly endothermic $\left(3.7 \mathrm{kcal} \mathrm{mol}^{-1}\right)$. $\mathrm{ClNO}_{2}$ easily decomposes to $\mathrm{Cl}$ and $\mathrm{NO}_{2}$. $\mathrm{ClNO}$ also reacts with itself to produce two $\mathrm{NO}$ and $\mathrm{Cl}_{2}$. Phosgene is more stable than other species and starts to react above $370^{\circ} \mathrm{C}$. The main reactions of consumptions are $\mathrm{Cl}$-atom abstractions by $\mathrm{NO}$ and $\mathrm{Cl}$-atoms, and $\mathrm{CCl}_{3}$ at the early stage of the reaction. The $\mathrm{COCl}$ radicals decompose then to $\mathrm{Cl}$-atom and $\mathrm{CO}$ or react with $\mathrm{NO}_{2}$ to form $\mathrm{COClONO}$, which decomposes to $\mathrm{CO}_{2}$ and $\mathrm{CINO}$ through a cyclic transition state. Tetrachloromethane is produced mainly at low temperature by the reaction of $\mathrm{CCl}_{3}$ with $\mathrm{ClNO}$. For temperature above $300^{\circ} \mathrm{C}$, it is consumed by $\mathrm{Cl}$-atom abstraction, to yield back $\mathrm{CCl}_{3}$. The reaction of the latter with $\mathrm{NO}_{2}$ yields $\mathrm{CCl}_{3} \mathrm{O}$, which decomposes into phosgene and Cl-atom.

In order to compare pyrolysis and combustion behavior of chloropicrin in incineration or accidental fire conditions, simulations were performed in a perfectly stirred reactor for mixtures of $5 \%$ of chloropicrin in air and in nitrogen under atmospheric pressure from $400 \mathrm{~K}$ to $1500 \mathrm{~K}$ for a residence time of $1 \mathrm{~s}$. Chloropicrin profiles are identical in both conditions since reactant consumption occurs uniquely by the initial bond breaking rather than any radical bimolecular reaction. Product distribution and consumption are very similar. Figure 8 depicts the reaction pathways in pyrolysis and combustion at $1000 \mathrm{~K}$. Chloropicrin reacts via the same reaction paths under both conditions sets by decomposition to $\mathrm{NO}_{2}$ and $\mathrm{CCl}_{3}$, followed by the combination to $\mathrm{CCl}_{3} \mathrm{ONO}$ and the formation of phosgene and nitrosyl chloride. The main difference appears in the products reactions. In these high temperature conditions, phosgene reacts by $\mathrm{Cl}$-atom abstractions by $\mathrm{NO}$ and $\mathrm{Cl}$ in both conditions, but the 
role of $\mathrm{NO}$ decreases slightly in air compared to pyrolysis. In presence of $\mathrm{O}_{2}$, the $\mathrm{NO}_{2} / \mathrm{NO}$ ratio is indeed strongly modified by the oxidation of $\mathrm{NO}$ to $\mathrm{NO}_{2}$. Reaction pathways of $\mathrm{ClNO}$ are affected: reaction with $\mathrm{Cl}$-atoms remains the main consumption channel, but reaction with $\mathrm{NO}_{2}$ accounts for $18 \%$ of CINO consumption in air, but is almost negligible in pyrolysis.

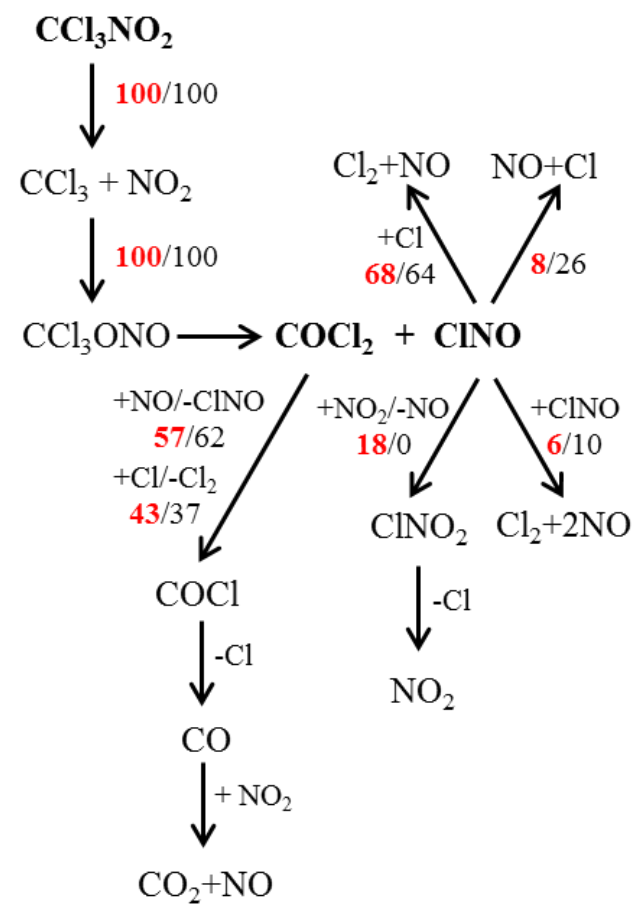

Figure 8. Flux analysis for the reaction of $5 \%$ of chloropicrin in nitrogen and in air at $1000 \mathrm{~K}$ in a PSR $(\mathrm{P}=1 \mathrm{~atm}, \tau=1 \mathrm{~s})$. Red bold numbers are flow rate $(\%)$ in combustion, black number in pyrolysis.

\section{Conclusions}

The first detailed kinetic model of the thermal decomposition and the combustion of chloropicrin has been developed and validated. The mechanism is composed of submechanisms from the literature describing the reactions of the nitrogen containing and chlorinated species. The comprehensive mechanism for the decomposition of chloropicrin includes unimolecular reactions, $\mathrm{Cl}$-atom abstractions, decomposition of the radicals formed, chlorine-nitrogen coupling reactions, as well as some oxidation reactions not included in the 
sub-mechanism of chlorinated and nitrogenous species. The kinetic constants were either taken from the literature or theoretically computed using the CBS-QB3 level of theory or evaluated by analogy with reactions included in the mechanism of the chlorinated species. Simulations are in good agreement with experimental results from the literature obtained in pyrolysis in an isothermal closed reactor. Chloropicrin decomposes easily at low temperature to reach a complete decomposition in few minutes in a vessel at temperatures as low as $200^{\circ} \mathrm{C}$. Its main products are phosgene, which is much more stable and reacts only at a higher temperature, above $370^{\circ} \mathrm{C}$, and nitrosyl chloride, which decomposes to $\mathrm{NO}, \mathrm{Cl}_{2}$ and $\mathrm{Cl}$ atoms. Simulations predict that chloropicrin reacts identically in pyrolysis and combustion, because of the absence of $\mathrm{H}$-atom and of little interaction of oxygen with decomposition intermediates. The effect of $\mathrm{O}_{2}$ is mainly a change in the $\mathrm{NO}_{2} / \mathrm{NO}$ ratio, which changes slightly reactions routes of phosgene and $\mathrm{ClNO}$, but does not significantly change the overall kinetics.

\section{Supplemental material}

The detailed chemical kinetic model is available as supplemental material.

\section{Acknowledgements}

This work was supported by DGA Maîtrise NRBC. This work was granted access to the HPC resources of IDRIS under the allocation 2017-A0010807249 made by GENCI. 


\section{References}

(1) Jackson, K. E. Chloropicrin. Chem. Rev. 1934, 14, 251-286.

(2) Raman, P. Chloropicrin. In Encyclopedia of Toxicology (Third edition); Elsevier: Oxford, 2014; pp 903-906.

(3) Pesonen, M.; Häkkinen, M.; Rilla, K.; Juvonen, R.; Kuitunen, T.; Pasanen, M.; Vähäkangas, K. Chloropicrin-Induced Toxic Responses in Human Lung Epithelial Cells. Toxicol. Lett. 2014, 226, 236-244.

(4) Gupta, R. C. Handbook of Toxicology of Chemical Warfare Agents; Academic Press, 2015.

(5) Triky-Dotan, S.; Westerdahl, B.; Martin, F. N.; Subbarao, K.; Koike, S. T.; Ajwa, H. A. Fumigant Dosages below Maximum Label Rate Control Some Soilborne Pathogens. Calif. Agric. 2016, 70, 130-136.

(6) Bunnett, J. F.; Mikolajczyk, M. Arsenic and Old Mustard: Chemical Problems in the Destruction of Old Arsenical and Mustard Munitions; Springer Science \& Business Media, 2013; Vol. 19.

(7) Gardner, J. A.; Fox, F. W. CVIII.-Chloropicrin. Part I. J. Chem. Soc. Trans. 1919, $115,1188-1194$.

(8) Radulescu, D.; Zamfirecu, G. Sur La Décomposition Thermique de La Chloropicrine. Bull Soc Chem Rom. 1935, 17, 87-92.

(9) Steacie, E. W. R.; Smith, W. M. The Unimolecular Decomposition of Gaseous Chloropicrin. J. Chem. Phys. 1938, 6, 145-149.

(10) Dubikhin, V. V.; Nazin, G. M.; Manelis, G. B. Thermal Decomposition of Chloropicrin. Bull. Acad. Sci. USSR Div. Chem. Sci. 1971, 20, 1245-1246.

(11) Battin-Leclerc, F.; Baronnet, F.; Paternotte, G.; Leclerc, J. P.; Gourhan, R. Thermal Decomposition of Chloropicrin, Diphosgene and Phosgene between 100 and $530^{\circ} \mathrm{C} . J$. Anal. Appl. Pyrolysis 2000, 53, 95-105.

(12) Ashmore, P. G.; Norrish, R. G. W. A Study of Sensitized Explosions. VIII. Experimental Work on the Hydrogen-Oxygen Reaction Sensitized by Chloropicrin. Proc. R. Soc. Lond. Ser. Math. Phys. Sci. 1950, 203, 454-471.

(13) Ashmore, P. G.; Norrish, R. G. W. A Study of Sensitized Explosions. X. The Kinetics of Decomposition of Chloropicrin and of the Hydrogen-Oxygen and HydrogenChlorine Reactions Sensitized by Chloropicrin. Proc. R. Soc. Lond. Ser. Math. Phys. Sci. 1950, 204, 34-50.

(14) Sirjean, B.; Lizardo-Huerta, J.-C.; Verdier, L.; Fournet, R.; Glaude, P.-A. Kinetic Modeling of the Thermal Destruction of Mustard Gas. Proc. Combust. Inst. 2017, 36, 499-506.

(15) Lizardo-Huerta, J.-C.; Sirjean, B.; Verdier, L.; Fournet, R.; Glaude, P.-A. Kinetic Modeling of the Thermal Destruction of Nitrogen Mustard Gas. J. Phys. Chem. A 2017, 121, 3254-3262.

(16) Lizardo-Huerta, J.-C.; Sirjean, B.; Verdier, L.; Fournet, R.; Glaude, P.-A. Thermal Decomposition of Phosgene and Diphosgene. J. Phys. Chem. A 2018, 122, 249-257.

(17) Montgomery, J. A.; Frisch, M. J.; Ochterski, J. W.; Petersson, G. A. A Complete Basis Set Model Chemistry. VI. Use of Density Functional Geometries and Frequencies. $J$. Chem. Phys. 1999, 110, 2822-2827.

(18) Montgomery, J. A.; Frisch, M. J.; Ochterski, J. W.; Petersson, G. A. A Complete Basis Set Model Chemistry. VII. Use of the Minimum Population Localization Method. $J$. Chem. Phys. 2000, 112, 6532-6542.

(19) Malick, D. K.; Petersson, G. A.; Jr, J. A. M. Transition States for Chemical Reactions I. Geometry and Classical Barrier Height. J. Chem. Phys. 1998, 108, 5704-5713. 
(20) Frisch, M.; Trucks, G.; Schlegel, H.; Scuseria, G.; Robb, M.; Cheeseman, J.; Scalmani, G.; Barone, V.; Mennucci, B.; Petersson, G.; et al. Gaussian 09, Revision B.01. 2009.

(21) Petersson, G. A.; Malick, D. K.; Wilson, W. G.; Ochterski, J. W.; Jr, J. A. M.; Frisch, M. J. Calibration and Comparison of the Gaussian-2, Complete Basis Set, and Density Functional Methods for Computational Thermochemistry. J. Chem. Phys. 1998, 109, 10570-10579.

(22) Cox, J. D.; Wagman, D. .; Medvedev, V. A. CODATA Key Values for Thermodynamics; Hemisphere: New York, 1989.

(23) Johnson III, R. D. NIST Computational Chemistry Comparison and Benchmark Database NIST Standard Reference Database Number 101, Release 16a http://cccbdb.nist.gov/ (accessed Mar 13, 2015).

(24) Khalfa, A.; Ferrari, M.; Fournet, R.; Sirjean, B.; Verdier, L.; Glaude, P. A. Quantum Chemical Study of the Thermochemical Properties of Organophosphorous Compounds. J. Phys. Chem. A 2015, 119, 10527-10539.

(25) Lizardo-Huerta, J.-C.; Sirjean, B.; Bounaceur, R.; Fournet, R. Intramolecular Effects on the Kinetics of Unimolecular Reactions of $\beta$-HOROO' and HOQ ${ }^{\circ} \mathrm{OOH}$ Radicals. Phys. Chem. Chem. Phys. 2016, 18, 12231-12251.

(26) Vansteenkiste, P.; Neck, D. V.; Speybroeck, V. V.; Waroquier, M. An Extended Hindered-Rotor Model with Incorporation of Coriolis and Vibrational-Rotational Coupling for Calculating Partition Functions and Derived Quantities. J. Chem. Phys. 2006, 124, 044314.

(27) Konnov, A. A.; Barnes, F. J.; Bromly, J. H.; Zhu, J. N.; Zhang, D. The PseudoCatalytic Promotion of Nitric Oxide Oxidation by Ethane at Low Temperatures. Combust. Flame 2005, 141, 191-199.

(28) Leylegian, J. C.; Zhu, D. L.; Law, C. K.; Wang, H. Experiments and Numerical Simulation on the Laminar Flame Speeds of Dichloromethane and Trichloromethane. Combust. Flame 1998, 114, 285-293.

(29) Pelucchi, M.; Frassoldati, A.; Faravelli, T.; Ruscic, B.; Glarborg, P. High-Temperature Chemistry of $\mathrm{HCl}$ and $\mathrm{Cl} 2$. Combust. Flame 2015, 162, 2693-2704.

(30) Drakon, A.; Eremin, A. Promotion of Methane Ignition by the Fire Suppressants CCl4 and CF3H. Combust. Flame 2015, 162, 2746-2747.

(31) Buda, F.; Bounaceur, R.; Warth, V.; Glaude, P. A.; Fournet, R.; Battin-Leclerc, F. Progress toward a Unified Detailed Kinetic Model for the Autoignition of Alkanes from C4 to C10 between 600 and 1200 K. Combust. Flame 2005, 142, 170-186.

(32) Kumaran, S. S.; Su, M.-C.; Lim, K. P.; Michael, J. V.; Wagner, A. F.; Harding, L. B.; Dixon, D. A. Ab Initio Calculations and Three Different Applications of Unimolecular Rate Theory for the Dissociations of CCl4, $\mathrm{CFCl}$, $\mathrm{CF} 2 \mathrm{Cl} 2$, and $\mathrm{CF} 3 \mathrm{Cl}$. J. Phys. Chem. 1996, 100, 7541-7549.

(33) Zhu, R. S.; Lin, M. C. CH3NO2 Decomposition/Isomerization Mechanism and Product Branching Ratios: An Ab Initio Chemical Kinetic Study. Chem. Phys. Lett. 2009, 478, 11-16.

(34) Zhang, J.-X.; Li, Z.-S.; Liu, J.-Y.; Sun, C.-C. Theoretical Mechanistic Study on the Radical-Molecule Reaction of $\mathrm{CHCl} 2 / \mathrm{CCl} 3$ with $\mathrm{NO} 2$. J. Comput. Chem. 2006, 27, 661-671.

(35) Liu, K.; Xiang, T.; Wu, W.; Zhao, S.; Su, H. Reaction Mechanisms of C2Cl3 + NO2 via Nitro and Nitrite Adducts. J. Phys. Chem. A 2008, 112, 10807-10815.

(36) Fernández-Ramos, A.; Martínez-Núñez, E.; Ríos, M. A.; Rodríguez-Otero, J.; Vázquez, S. A.; Estévez, C. M. Direct Dynamics Study of the Dissociation and Elimination Channels in the Thermal Decomposition of Methyl Nitrite. J. Am. Chem. Soc. 1998, 120, 7594-7601. 
(37) Brudnik, K.; Twarda, M.; Sarzyński, D.; Jodkowski, J. T. Theoretical Study of the Kinetics of Chlorine Atom Abstraction from Chloromethanes by Atomic Chlorine. $J$. Mol. Model. 2013, 19, 4181-4193.

(38) Zhu, R. S.; Lin, M. C. Ab Initio Studies of ClOx Reactions: Prediction of the Rate Constants of $\mathrm{ClO}+\mathrm{NO}$ for the Forward and Reverse Processes. ChemPhysChem 2004, 5, 1864-1870.

(39) Zhu, R. S.; Lin, M. C. Ab Initio Studies of ClOx Reactions: Prediction of the Rate Constants of $\mathrm{ClO}+\mathrm{NO} 2$ for the Forward and Reverse Processes. ChemPhysChem 2005 , 6, 1514-1521.

(40) Manion, J. A.; Huie, R. E.; Levin, R. D.; Burgess Jr, D. R.; Orkin, V. L.; Tsang, W.; McGivern, W. S.; Hudgens, J. W.; Knyazev, V. D.; Atkinson, D. B.; et al. NIST Chemical Kinetics Database, NIST Standard Reference Database 17, Version 7.0 (Web Version), Release 1.6.8, Data version 2015.12, National Institute of Standards and Technology, Gaithersburg, Maryland, 20899-8320.

(41) Kee, R. J.; Rupley, F. M.; Miller, J. A. CHEMKIN II. A Fortran Chemical Kinetics Package for the Analysis of Gas-Phase Chemical Kinetics; Sandia Laboratories Report, SAND 89-8009B, 1993. 